\title{
Marc Escrihuela-Villar* \\ On Merger Profitability and the Intensity of Rivalry
}

DOI 10.1515/bejeap-2015-0209

Published online February 16, 2016

Abstract: This note considers a general symmetric quantity-setting oligopoly where the "coefficient of cooperation" defined by Cyert and DeGroot (1973, "An Analysis of Cooperation and Learning in a Duopoly Context". The American Economic Review 63:24-37) is interpreted as the parameter indicating severity of competition. It is obtained that horizontal mergers are more likely to be profitable in a more competitive market structure. Consequently, the results by Salant et al. (1983, "The Effects of an Exogenous Change in Industry Structure on Cournot-Nash Equilibrium". The Quarterly Journal of Economics 98 (2):185-99) about merger profitability are sensitive to the assumption of pre-merger Cournot competition.

Keywords: oligopoly, competitive intensity, horizontal mergers JEL Classification: L13, L40, L41

\section{Introduction}

In a symmetric linear Cournot oligopoly with homogenous goods, Salant, Switzer, and Reynolds (1983) (henceforth, SSR) showed that horizontal mergers are generally not profitable and that the minimum profitable merger involves at least 80 percent of the firms. Mergers typically are not profitable for insiders but are profitable for non-merging firms. Unprofitability comes from the fact that non-merging firms react to the merger by increasing their output. This is often known as the merger paradox and makes it hard to explain how merger activity gets started, since a firm would always prefer to remain an outsider. ${ }^{1}$ This approach, however, leaves out the

1 This paradox though is weakened for instance by convex demand (Fauh-Oller, 1997) or cost functions (Perry and Porter 1985). Furthermore, this result is valid only in Cournot environments and generally fails to hold in differentiated Bertrand models. Deneckere and Davidson (1985) show that when reaction functions are upward sloping, mergers of any size are beneficial.

*Corresponding author: Marc Escrihuela-Villar, Departamento de Economia Aplicada, Universitat de les Illes Balears, Edificio Jovellanos Ctra. Valldemossa km 7.5. 07122 Palma de Mallorca, Baleares, Spain, E-mail: marc.escrihuela@uib.es 
competitive intensity and assumes Cournot behaviour. In fact, most of the literature considers the absence of collusion as the most plausible scenario in which mergers take place and only very few papers address related aspects of mergers in a (possibly) collusive environment. Among the exceptions, Escrihuela-Villar (2008) analyses the price effects of mergers in a dynamic collusive environment. Also Kwoka (1989) and Rodrigues (2001), that using the conjectural variations approach and linear demand functions, illustrate the determinants of merger occurrence showing that the equilibrium market concentration is increasing in the expected competitive intensity. The main purpose of this note is to fill this gap in the literature by studying the effect of pre-merger competitive intensity on merger profitability in a quantity-setting market under fairly general conditions.

Following a recent trend in the literature, we model the intensity of competition assuming that firms care about their profits plus a weighted average of the profits of the other firms. ${ }^{2}$ Using a payoff function based on relative performance, the intensity of competition can be parameterised. Intermediate values of this parameter then, might represent imperfect collusion and may be justified by reference to some implicit dynamic zmodel of collusion, a reduced-form representation of which being the quantity competition subgame of this model. This formulation is closely related to the "coefficient of cooperation", defined by Cyert and DeGroot (1973) and has also been justified by other arguments. For instance, it captures the relative performance approach that is evolutionary stable (Vega-Redondo 1997). Furthermore, it can also be assumed that sufficiently patient firms always achieve the highest level of collusion that is sustainable as equilibrium of an infinitely repeated game given a number of parameters taken as exogenous at the competition stage. Under this interpretation, a fall in the importance given to rivals' profits might correspond to a lower critical discount factor in an infinitely repeated game.

Our main result shows that the incentive to merge is increasing in the intensity of competition for a wide class of demand functions. Intuitively, in industries where firms are already cooperating, mergers add less to the high profits that firms are otherwise achieving. A simple illustration is provided using a linear demand function to show that the result of SSR mentioned above is only valid in Cournot environments and fails to hold in a quantity-setting model with a different competitive intensity since the well-known output expanding response of non-merging firms is smaller in a more competitive market. Consequently, the

2 See for instance Symeonidis (2008) for a duopoly or Matsumura, Matsushima, and Cato (2013) for an oligopoly. Equivalently, d'Aspremont and Ferreira (2009) add some positive weight also to the total surplus. 
minimum required proportion of participants in the merger decreases with the intensity of competition. ${ }^{3}$ A possible implication for policy makers is that, since mergers may be seen as an alternative to cooperation, it seems plausible to expect greater merger movements in more competitive markets.

Despite its theoretical viewpoint, this note is also motivated by real cases. Empirical evidence is copious suggesting that merger incentives are related to the pre-merger degree of competition, showing that in industries characterised by cartelist activities firms resort to mergers when cartels become less viable. Bittlingmayer (1985) shows that during the Great Merger Wave (1898-1902), mergers in several (cartelised) industries in the US (cotton oil, sugar, cast iron pipe, oil, meat packaging or steel and railroading), appear to have been the result of antitrust actions taken against cartels after the Sherman Act was passed. Equivalently, the Restrictive Trade Practices Act (1956), which outlawed cartels, triggered a wave of mergers in the UK (see Symeonidis 2002). In the same line, Evenett, Levenstein, and Suslow (2001) examine international cartels during the 1990s and observe that mergers are among the different measures adopted by firms for survival in collusive industries where cartel formation is restricted. A similar trend regarding the substitutability between merging and colluding has also been noticed in Germany where Neumann (2001) argues that German industries like cement, food processing machine building, etc. adopted cartelist activities in order to attain monopolistic power only when mergers were not possible. One could argue thus that a stricter legal enforcement against a cartel increases the relative cost of collusion as compared to merger and consequently firms resort to mergers.

\section{Model and results}

Assume an $n$-firm homogenous product oligopoly where $2 \leq n$. The inverse demand function is given by $P(Q)$ where $Q=\sum_{i=1}^{n} q_{i}$ is the industry output and $q_{i}$ is the output of the ith firm. The demand function is twice continuously differentiable, downward sloping, and has a downward sloping associated

3 We also note that this result resembles a well-known result in the literature on managerial compensation where the increased profit from any reduction in the number of firms is higher under delegation (see for instance Ziss 2001 or Straume 2006). In these papers thus, the profitability of merger in oligopoly is significantly enhanced if firms delegate output decisions to a manager. 
marginal revenue function. Production costs are normalised to 0. Demand at price 0 is positive but finite and satisfies $2 P^{\prime}(Q)+P^{\prime \prime}(Q) Q<0$ so that the secondorder conditions always hold implying that $\beta(Q)>-2$, where $\beta(Q) \equiv \frac{P^{\prime \prime}(Q) Q}{P^{\prime}(Q)}$ is defined as the degree of concavity of demand. The profit function of firm $i$, to be maximised by choice of $q_{i}$, is:

$$
\Pi_{i}\left(q_{i}, Q_{-i}\right)=P(Q)_{q i}
$$

with $Q_{-i}=Q-q_{i}$ representing the quantity supplied by the $(n-1)$ competitors of firm $i$.

In this baseline framework, a particular way of modelling the intensity of competition is considered. Following the approach of the coefficient of cooperation defined in Cyert and DeGroot (1973), we obtain a model in which firms are concerned about relative profits (the average profits of the other firms) as well as their own profits. ${ }^{4}$

The payoff function that firm $i$ maximises is given by $\Pi_{i}-\frac{\lambda}{n-1}\left(\sum_{j \neq i}^{n} \Pi_{j}\right)$, where $\Pi_{i}$ is the profit of firm $i=1,2, \ldots, n$ and $\lambda \in[1-n, 1]$ that we assume to be symmetric across firms. The parameter $\lambda$ thus can be interpreted as representing the degree of reciprocal preference. A positive $\lambda$ is equivalent to firms envying their rivals' success, whereas a negative $\lambda$ occurs when firms have reciprocal (namely, altruistic) payoff functions. ${ }^{5}$ The present model encompasses the

\footnotetext{
4 Escrihuela-Villar (2015) shows that using conjectural variations and the coefficient of cooperation leads to equivalent closed-form solutions. However, the rationale behind in order to model the degree of competition in the market is fairly different. Additionally, several authors have already shown the preference of the present approach instead of the conjectural variations approach. As an example, Symeonidis (2000) pp. 58 footnote 4 states that this formulation "is free of some of the theoretical problems encountered in other approaches to modelling the intensity of short-run competition by way of a reduced-form parameter, such as the conjectural variations approach”.

5 Admittedly $\lambda>0$ might seem counterintuitive at first sight. We follow here however the justifying reasoning of Matsumura and Matsushima (2012): (i) objective functions are often based on relative performance since, for instance, evaluations of management activities are also based on their relative performances, (ii) experimental works already pointed out reciprocal (but not necessarily altruistic) behaviour (see for instance Cason, Saijo, and Yamato 2002) that is closely related to firms' objective functions based on relative performance, (iii) following Fershtman and Judd (1987) where managers are paid in proportion to a combination of profits and sales, we can replace sales with (negative) profit of the rival in their model and the firms would in fact adopt a positive $\lambda$, (iv) it can be shown that an increase in $\lambda$ makes collusion less stable in a repeated game also when $\lambda$ is positive. This suggests thus that a larger $\lambda$ indicates more intensive competition.
} 
Cournot case if $\lambda=0$, the joint profit maximizing allocation if $\lambda=1-n$ and the perfectly competitive outcome for $\lambda=1{ }^{6}$ Hence $\lambda$ may represent the severity of competition and enables us to treat the severity of competition as a continuous variable. Additionally, we consider the possibility that a group of $m+1$ firms merge without cost synergies associated. Once $m+1$ firms have merged there will be $n-m$ firms that behave like we described above. Admittedly, since the range of values of $\lambda$ depends on $n$ it could also be argued that the pre-merger degree of competition is modified after the merger. ${ }^{7}$ This, however, is not our approach. Instead, we consider how the expected pre-merger competitive intensity affects the incentives to merge. A merger is considered to be profitable if the profits of merging firms increase after merger. Since the function in eq. [1] depends on $n$ and $\lambda$, we can denote the incentives to merge for $m+1$ firms by:

$$
\prod_{i}(n-m, \lambda)-(m+1) \prod_{i}(n, \lambda) .
$$

We assume $\beta(Q) \geq \beta>-2$ for any $Q$. In other words, $\beta$ is the lower bound of the degree of concavity and a set of demands satisfying $\beta(Q) \geq \beta$ is considered. We obtain:

Proposition 1: The incentive to merge defined by eq. [2] is increasing in $\lambda$.

Proof: See Appendix. The intuition can be easily illustrated applying our model to the linear demand case as in $\operatorname{SSR}(\beta(Q)=0) .{ }^{8}$ Assume that $P(Q)=a-Q$. Then, firm's output in equilibrium is given by:

$$
q_{i}=\frac{a}{1-\lambda+n}
$$

6 Note that the first-order condition for a firm $\mathrm{i}$ when $\lambda=1$ becomes $p(Q)+\frac{\partial_{p}(Q)}{\partial_{q_{i}}}$ $\left(q_{i}-\frac{1}{n-1} \sum_{j \neq i}^{n} q_{j}\right)=0$. In a symmetric equilibrium $q_{j}=q_{i}$ and therefore $p(Q)+\frac{\partial_{p}(Q)}{\partial q_{i}}\left(q_{i}-q_{i}\right)$ $=0$ implies that price is equal to marginal cost ( 0 in our case) and thus, a firm behaves as if it is a price taker.

7 In this line, the literature on horizontal merger assessment is huge and has often focused on coordinated effects (if a merger induces rivals to alter their strategies, resulting in some form of price-increasing coordination). As an example Vives (2001) obtains that reducing the number of competitors facilitates collusion.

8 Using the present formulation, it can also be easily checked that the result in Fauli-Oller (1997) where the degree of concavity of the demand function reduces merger profitability in a Cournot setting can also be generalized to a model with several competition intensities. 
Firms’ profits are given by ${ }^{9}$ :

$$
\prod_{i}(n, \lambda)=\frac{a^{2}(1-\lambda)}{(1-\lambda+n)^{2}}
$$

We can easily obtain:

Proposition 2: If $\beta(Q)=0$, the merger of $m+1$ firms is profitable if $m \geq \bar{m} \equiv n-\lambda+\frac{1}{2}(1-\sqrt{5+4(n-\lambda)})$. Hence, the minimum proportion of participants in order for the merger to be profitable $\left(\frac{\bar{m}+1}{n}\right)$ decreases with $\lambda$.

Proof: See Appendix. In a Cournot setting even though mergers increase price, they are (generally) not profitable because outsiders react to the merger by expanding their output. This is still true in our model because in eq. [3] $\frac{\partial q_{i}}{\partial n}=-\frac{1}{(1+n-\lambda)^{2}}<0$. However, $\frac{\partial^{2} q_{i}}{\partial n \partial \lambda}=\frac{2 a}{(\lambda-1-n)^{3}}<0$ when $\lambda \in[1-n, 1]$. In words, the reaction of non-merging firms is to expand production but in a more competitive market this expansion is smaller rendering mergers more profitable. In fact for instance if $P=a-Q$, the reaction function of a firm $i$ can be expressed as follows: $q_{i}=\frac{q(n-1)+(1-n+\lambda) \sum_{j \neq i}^{n} q_{j}}{2(n-1)}$. It can be thus easily checked that this reaction function is downward sloping since $\frac{\partial q_{i}}{\partial q_{j}}=\frac{(1-n+\lambda)}{2(n-1)}<0$ whenever $\lambda \in[1-n, 1]$. Then, as $\lambda$ increases, the reaction function of a firm becomes gentler and the free rider effect is weaker.

The result of SSR thus is only valid in a Cournot competition environment. If $\lambda>0$, a higher degree of competition compared to Cournot competition increases firms' incentives to merge. $\lambda<0$ firms are already sustaining a collusive agreement and mergers lose attractiveness as an anti-competitive device. ${ }^{10}$

Admittedly, we treat $\lambda$ as an exogenous parameter and although we build a direct link to the degree of competition, the reader might feel more comfortable when such link is made explicit and based on a direct behavioural assumption like the output produced. It can be easily shown that Proposition 2 also holds in

9 Note that the outcome gradually approaches the competitive outcome as increases. So, in the view of behaviourism (or the revealed preference approach), $\lambda$ can be regarded as the parameter of competitiveness. Additionally, we can also justify $\lambda$ as a measure of the intensity of competition since the equilibrium price is monotonically decreasing with $\lambda$, while an increase in competitiveness increases consumer surplus and decreases producer surplus.

10 In fact, in the linear case if $\lambda$ is low enough mergers are never profitable since the required proportion of firms involved in the merger is larger than 1 . More precisely, if $\lambda \in[1-n, 1-\sqrt{n}]$ mergers among firms are never profitable. 
a model where firms' strategy set is $q \in\left[\frac{1}{2 n}, \frac{1}{n}\right]$, a quantity in the interval between full collusion and perfect competition. ${ }^{11}$ Therefore, the profitability of horizontal mergers crucially depends on the pre-merger output (namely, the intensity of competition).

\section{Conclusions}

A theoretical framework has been developed to study merger profitability in an imperfectly competitive environment. We found that mergers are more likely profitable in rivalrous environments. Consequently, the results in SSR are sensitive to the assumption of pre-merger Cournot competition. The well-known merger paradox regarding merger profitability thus might be alleviated or exacerbated if the pre-merger degree of competition is considered. It is to be expected thus more intense merger movements where collusion is absent. ${ }^{12}$ The results presented are also robust to other approaches to the intensity of competition like conjectural variations and seem consistent with existing empirical evidence regarding the substitutability between merging and colluding.

\section{Appendix}

Proof of Proposition 1: From eq. [1] we obtain the first-order condition (FOC) for firm $i ; \frac{\partial \prod_{i}\left(q_{i}, Q_{-i}\right)}{\partial q_{i}}=P(Q)+\frac{\partial P\left(Q_{-i}+q_{i}\right)}{\partial q_{i}} q_{i}-\frac{\lambda}{n-1}\left[\sum_{j \neq i}^{n} \frac{\partial P\left(Q_{-j}+q_{j}\right)}{\partial q_{j}} q_{j}\right]=0$. Since pre-merger equilibrium is symmetric, $\left(q_{i}=q_{j} \forall i \neq j\right)$, FOC becomes $P(Q)+\frac{\partial P\left(Q_{-i}+q_{i}\right)}{\partial q_{i}} q_{i}$ $[1-\lambda]=0$ where since $q_{i}=\frac{Q}{n}$ and using the notation $\frac{\partial P\left(Q_{-i}+q_{i}\right)}{\partial q_{i}}=P^{\prime}(Q)$, we can also express as:

$$
P(Q)+P^{\prime}(Q) \frac{Q}{n}[1-\lambda]=0 .
$$

As in Faulí-Oller (1997), eq. [5] defines implicitly the quantity in equilibrium as a function of the number of firms $Q(n)$. We abuse notation and suppress the

11 Further details are available upon request.

12 We note also that the mergers considered here are all welfare reducing as they involve a reduction in output and no efficiency gains. However, following Farrell and Shapiro (1990), we could still examine the effects of merger on the nonparticipant firms and consumers, whom they call "outsiders". It can be easily checked that in a very competitive market, outsiders can also benefit from the merger since in a very competitive market the increase in price could be more than compensated by the increase in firms' profits due to the merger. 
functions in the derivatives. Differentiating eq. [5] with respect to $n$ we obtain $\left[P Q^{\prime \prime} \frac{Q}{n}+P^{\prime} \frac{Q^{\prime}}{n}-\frac{P^{\prime} Q}{n^{2}}\right][1-\lambda]+P^{\prime} Q^{\prime}=0$ Rearranging terms, $\frac{Q^{\prime}}{Q}=\frac{P^{\prime}(1-\lambda)}{n^{2}\left[P^{\prime \prime} \frac{Q}{n}[1-\lambda]+\frac{P^{\prime}(1-\lambda]}{n}+P^{\prime}\right]}$ can be interpreted as the proportional increase in output due to a marginal increase in $\mathrm{n}$. Since $\beta \equiv \frac{P^{\prime \prime} Q}{P^{\prime}}$, the last equation is:

$$
\frac{Q^{\prime}}{Q}=\frac{1-\lambda}{n[\beta[1-\lambda]+[1-\lambda]+n]}
$$

Equilibrium profits for each firm are $\prod_{i}(n, \lambda)=\frac{P(Q(n))}{n}$. If we differentiate profits with respect to $n$, and simplifying notation we obtain $\Pi^{\prime}=P^{\prime} Q^{\prime} \frac{Q}{n}+Q^{\prime} \frac{P}{n}-\frac{P Q}{n^{2}}$. The proportional increase in firms' profits due to a marginal increase in $n$ is given by: $\frac{\prod^{\prime}}{\prod}=\frac{Q^{\prime}}{Q}\left[\frac{P^{\prime} Q}{P}+1\right]-\frac{1}{n}$. Using eqs [5] and [6] we obtain $\frac{\prod^{\prime}}{\prod}=$ $\frac{1-\lambda}{n[\beta[1-\lambda]+[1-\lambda]+n]}\left[1-\frac{n}{1-\lambda}\right]-\frac{1}{n}$ and $-\frac{\prod^{\prime}}{\prod}=\frac{\beta[1-\lambda]+2 n}{n[1+\beta-\lambda[1+\beta]+n]}$. By integrating the previous expression we obtain: $\int_{-m}^{N} \frac{\beta[1-\lambda]+2 n}{n[1+\beta-\lambda[1+\beta]+n]} d n$. Consequently, the proportional increase in profits due to a merger of $m+1$ firms is $\frac{\prod(N-m)}{\prod(N)}=$ $\exp \left[\int_{N-m}^{N} \frac{\beta[1-\lambda]+2 n}{n[1+\beta-\lambda[1+\beta]+n]} d n\right]$. A merger of $m+1$ firms is profitable if exp $\left[\int_{N-m}^{N} \frac{\beta[1-\lambda]+2 n}{n[1+\beta-\lambda[1+\beta]+n]} d n\right] \geq(m+1)$. As in Faulí-Oller (1997), we solve the integral to obtain that if the degree of concavity is constant a merger is profitable if $g(N, m, \beta, \lambda) \geq(m+1)$ where $g(N, m, \beta, \lambda) \equiv\left(\frac{N}{N-m}\right)^{\frac{\beta}{1+\beta}}\left(\frac{1+\beta-\lambda(1+\beta)+N}{1+\beta-\lambda(1+\beta)-m+N}\right)^{\frac{\beta+2}{\beta+1}} \quad$ is not constant but it is not lower than $\beta$, we have $\frac{\prod^{(N-m)}}{\prod(N)} \leq g(N, m, \beta, \lambda)$. Finally, $\frac{\partial_{g}(N, m, \beta, \lambda)}{\partial \lambda}=\frac{(2+\beta) m\left(\frac{N}{N-m}\right)^{\frac{\beta}{1+\beta}}\left(\frac{1+\beta-\lambda(1+\beta)+N}{1+\beta-\lambda(1+\beta)-m+N}\right)^{\frac{1}{\beta+1}}}{(\lambda-\beta+\lambda \beta+m-N-1)^{2}}>0, \forall \beta>-2$.

Proof of Proposition 2: Since $g(n, m, 0, \lambda)=\frac{(1-\lambda+n)^{2}}{(1-\lambda-m+n)^{2}}$ the merger of $m+1$ firms is profitable if $\frac{(1-\lambda+n)^{2}}{(1-\lambda-m+n)^{2}} \geq m+1$ or $m \geq \bar{m} \equiv n-\lambda+\frac{1}{2}(1-\sqrt{5+4(n-\lambda)})$. The minimum proportion of firms involved in the profitable merger is $\frac{\bar{m}+1}{n}=\frac{3+2(n-\lambda)-\sqrt{5+4(n-\lambda)}}{2 n}$. Hence, is $\frac{\partial \frac{\bar{m}+1}{n}}{\partial \lambda}=\frac{1}{n \sqrt{5+4(n-\lambda)}}-\frac{1}{n}<0$. 
Acknowledgements: I am grateful to Ramon Faulí-Oller for his advice and encouragement. Financial support by the "Ministerio de Educación, Cultura y Deporte" through its project "Análisis de Economia Pública y Bienestar" (Ref: ECO2012-36480) is gratefully acknowledged. The usual disclaimer applies.

Funding: Ministerio de Educación, Cultura y Deporte (Grant/Award Number: 'ECO2012-36480').

\section{References}

d'Aspremont, C., and R. Dos Santos Ferreira. 2009. "Price-Quantity Competition with Varying Toughness". Games and Economic Behavior 65 (1):62-82.

Bittlingmayer, G. 1985. "Did Antitrust Policy Cause the Great Merger Wave?" Journal of Law and Economics 28 (1):77-118.

Cason, T. N., T. Saijo, and T. Yamato. 2002. "Voluntary Participation and Spite in Public Good Provision Experiments: An International Comparison”. Experimental Economics 5 (2):133-53.

Cyert, R. M., and M. H. DeGroot. 1973. "An Analysis of Cooperation and Learning in a Duopoly Context”. The American Economic Review 63:24-37.

Deneckere, R., and C. Davidson. 1985. "Incentives to Form Coalitions with Bertrand Competition". The RAND Journal of Economics 16 (4):473-86.

Escrihuela-Villar, M. 2008. "Partial Coordination and Mergers Among Quantity Setting Firms". International Journal of Industrial Organization 26 (3):803-10.

Escrihuela-Villar, M. 2015. "A Note on the Equivalence of the Conjectural Variations Solution and the Coefficient of Cooperation". The B.E. Journal of Theoretical Economics 15 (2):473-80.

Evenett, S. J., M. C. Levenstein, and V. Y. Suslow. 2001. "International Cartel Enforcement: Lessonsfrom the 1990s”. The World Economy 24 (9):1221-45.

Farrell, J., and C. Shapiro. 1990. "Horizontal Mergers: An Equilibrium Analysis". The American Economic Review 80 (1):107-26.

Faulí-Oller, R. 1997. “On Merger Profitability in a Cournot Setting”. Economics Letters 54:75-9.

Fershtman, C., and K. L. Judd. 1987. "Equilibrium Incentives in Oligopoly". The American Economic Review 77:927-40.

Kwoka, J. E. 1989. "The Private Profitability of Horizontal Mergers with Non-Cournot and Maverick Behavior”. International Journal of Industrial Organization 7 (3):403-11.

Matsumura, T., and N. Matsushima. 2012. "Competitiveness and Stability of Collusive Behavior”. Bulletin of Economic Research 64 (1):22-31.

Matsumura, T., N. Matsushima, and S. Cato. 2013. "Competitiveness and R\&D Competition Revisited”. Economic Modelling 31:541-7.

Neumann, M. 2001. Competition Policy: History, Theory and Practice. Cheltenham, UK: Edward Elgar Publishing.

Perry, M. K., and R. H. Porter. 1985. "Oligopoly and the Incentive for Horizontal Merger".

The American Economic Review 75:219-27. 
Rodrigues, V. 2001. "Endogenous Mergers and Market Structure”. International Journal of Industrial Organization 19 (8):1245-61.

Salant, S., S. Switzer, and R. Reynolds. 1983. "The Effects of an Exogenous Change in Industry Structure on Cournot-Nash Equilibrium”. The Quarterly Journal of Economics 98 (2):185-99.

Straume, O. R. 2006. "Managerial Delegation and Merger Incentives with Asymmetric Costs". Journal of Institutional and Theoretical Economics 162 (3):450-69.

Symeonidis, G. 2000. "Price and Nonprice Competition with Endogenous Market Structure". Journal of Economics and Management Strategy 9:53-83.

Symeonidis, G. 2002. The Effects of Competition: Cartel Policy and the Evolution of Strategy and Structure in British Industry. Cambridge, MA: MIT Press Books, 1.

Symeonidis, G. 2008. "Downstream Competition, Bargaining, and Welfare”. Journal of Economics and Management Strategy 17 (1):247-70.

Vega-Redondo, F. 1997. “The Evolution of Walrasian Behaviour”. Econometrica 65:375-84. Vives, X. 2001. Oligopoly Pricing: Old Ideas and New Tools. Cambridge, MA: MIT Press. Ziss, S. 2001. “Horizontal Mergers and Delegation”. International Journal of Industrial Organization 19:471-92. 